Corrigendum

\title{
Corrigendum to "Toltrazuril and sulphonamide treatment against naturally Isospora suis infected suckling piglets: Is there an actual profit?" [Vet. Parasitol. 164 (2009) 362-365]
}

\author{
Antonio Scala ${ }^{\mathrm{a}, *}$, Francesca Demontis ${ }^{\mathrm{a}}$, Antonio Varcasia ${ }^{\mathrm{a}}$, Anna Paola Pipia ${ }^{\mathrm{a}}$, \\ Giovanni Poglayen ${ }^{\mathrm{b}}$, Nicola Ferrari ${ }^{\mathrm{c}}$, Marco Genchi $^{\mathrm{c}}$ \\ ${ }^{a}$ Department of Animal Biology, Section of Parasitology and Parasitic Diseases, Università degli Studi, 07100 Sassari, Italy \\ ${ }^{\mathrm{b}}$ Department of Public Veterinary Health and Animal Pathology, Università degli Studi, I-40064 Ozzano dell'Emilia, Italy \\ ${ }^{\mathrm{c}}$ Department of Animal Pathology, Università degli Studi, 20133 Milano, Italy
}

The author regrets that errors occurred in the abstract of the original article; incorrect dosage for sodium sulfamethazine and trimethoprim. The corrected full abstract appears below.

\begin{abstract}
A study was carried out to assess the efficacy and the economic profit of prophylactic treatment against Isopsora suis with toltrazuril or with a sulfamethazine/trimethoprim combination in piglets from an intensive pig farm. Thirty-one litters were included in study. Eight litters were treated once with toltrazuril (20 mg/kg b.w.) at 3 days of age (Toltra group); 8 litters were treated with $2 \mathrm{ml} /$ animal of a sulphonamide combination (sodium sulfamethazine $250 \mathrm{mg}$ and trimethoprim $50 \mathrm{mg} / \mathrm{kg}$ b.w.) for 3 consecutive
\end{abstract}

days starting at 3 days of age (Sulfa group), and 15 litters were untreated (control group). Counts of oocyst per gram on pooled feces sampled from each litter were carried out on Days 7, 14, 21 and 28 and diarrhea was registered daily from pooled samples. Piglets were weighed on Days 1, 7 and 28 and mean weight gain (WG) and daily weight gain (DWG) were evaluated. The economic profit of treatment was evaluated comparing the WG of piglets of each treatment group from the day of birth to Day 28. On Days 14, 21 and 28, toltrazuril showed a better efficacy in controlling fecal oocyst output, diarrhea and weight gain compared with sulphamidic treatment $(P<0.001)$. The budgeting analysis showed a return of economic benefit of $€ 0.915$ per toltrazuril-treated piglets and an additional cost of $€ 1.155$ per sulphonamide-treated piglets.
DOI of original article: 10.1016/j.vetpar.2009.04.028

* Corresponding author at: Dipartimento di Biologia Animale, Sezione di Parassitologia e Malattie Parassitarie, Università degli Studi di Sassari, Via Vienna 2, 07100 Sassari, Italy. Tel.: +39 079229465;

fax: +39 079229464 .

E-mail address: scala@uniss.it (A. Scala). 